\title{
Substance Use in Individuals with Mild to Borderline Intellectual Disability: an Exploration of Rates and Risks in the Netherlands
}

\author{
Joanneke E. L. VanDerNagel ${ }^{1,2}$ - Marion Kiewik ${ }^{1,3}$ • Robert Didden ${ }^{4,5}$. \\ Hubert P. L. M. Korzilius ${ }^{6}$ - Marike van Dijk ${ }^{2}$ • Job van der Palen ${ }^{7,8}$ • \\ Jan K. Buitelaar ${ }^{9,10}$ • Cor A. J. de Jong ${ }^{1,4}$
}

Published online: 19 October 2017

(C) The Author(s) 2017. This article is an open access publication

\begin{abstract}
Little is known about rates and risk factors of substance use (SU) in individuals with mild to borderline intellectual disabilities (MBID, IQ 50-85). This hinders targeted prevention and treatment. In this study we assessed SU rates and risk factors in individuals with MBID in 419 adults $(63 \%$ male, average IQ $=66$ ) in 16 Dutch disability services. Lifetime and current SU, SU picture recognition, knowledge, attitudes and modeling were assessed with the Substance use and misuse in Intellectual Disability - Questionnaire (SumIDQ). Lifetime licit SU (alcohol and tobacco) was 97\%, lifetime illicit SU (predominantly cannabis) was $50 \%$. Current users of tobacco (62\%), alcohol (64\%), and cannabis (15\%) initiated $\mathrm{SU}$ at a younger age than those who desisted $\mathrm{SU}(\mathrm{ps}<.001)$. Participants with mild ID and those with borderline ID did not differ in SU rates (ps .429-.812), or age at SU initiation (ps .221-.853). Current licit SU and lifetime illicit SU were related to male gender, younger age, and (for smoking and stimulant use) to lack of daytime activities. However, these factors did not contribute to multivariate models when recognition, knowledge, attitudes and modeling were added. The models correctly identified current SU in $84 \%$ (smoking) and $74 \%$
\end{abstract}

Joanneke E. L. VanDerNagel

j.vandernagel@tactus.nl

1 Nijmegen Institute for Scientist-Practitioners in Addiction, Radboud University, P.O. Box 6909, 6503 GK Nijmegen, the Netherlands

2 Tactus Addiction Treatment, Raiffeisenstraat 75, 7514 AM Enschede, the Netherlands

3 Aveleijn, Grotestraat 260, 7622 GW Borne, the Netherlands

4 Behavioural Science Institute, Radboud University, P.O. Box 9104, 6500 HE Nijmegen, the Netherlands

5 Trajectum, P.O. Box 40012, 8004 DA Zwolle, the Netherlands (drinking), and lifetime SU in 76\% (cannabis) and 84\% (stimulants) of the participants. As almost all participants reported lifetime use of licit, and about half reported lifetime illicit substance use, systematic screening for substance use, and development of preventative and treatment interventions targeted to this group are needed.

Keywords Substance use - Intellectual disability · Assessment $\cdot$ Risk factors $\cdot$ Prevalence $\cdot$ Epidemiology

\section{Introduction}

Individuals with mild to borderline intellectual disability (MBID) have been identified as a risk group for negative consequences of substance use (SU), and substance use disorder (SUD) (Burgard et al. 2000; Carroll Chapman and Wu 2012; Hassiotis et al. 2011; McGillicuddy 2006; Mcgillivray and Moore 2001; Van Duijvenbode et al. 2015). Unfortunately, little is known about SU prevalence and risk factors in individuals with MBID. This hinders addiction med-
6 Institute for Management Research, Radboud University, Thomas van Aquinostraat 5, 6525 GD Nijmegen, the Netherlands

7 Department of Research Methodology, Measurement and Data Analysis, Faculty of Behavioral Sciences, University of Twente, P.O. Box 217, 7500 AE Enschede, the Netherlands

8 Medical School Twente, Medisch Spectrum Twente, P.O. Box 50000, 7500 KA Enschede, the Netherlands

9 Department of Cognitive Neuroscience, Radboud University Medical Centre, P.O. Box 9101 (204), 6500 HB Nijmegen, the Netherlands

10 Karakter Child and Adolescent Psychiatry, Reinierpostlaan 12, 6525 GC Nijmegen, the Netherlands 
icine and MBID services to take preventative actions and implement targeted treatment.

According to the DSM5 (American Psychiatric Association 2013), an intellectual disability (ID) involves 1) impairments of general mental abilities, that 2) impact adaptive functioning in the conceptual, social and practical domain, and that 3 ) occur during the developmental period. While its severity is based on (impairments in) adaptive functioning, in the DSM5 text description the former DSM-IV criterion of an IQ-test score approximately two standard deviations below the population mean (i.e., an IQ of 70 or below) is still used. Borderline intellectual functioning is defined as an IQ in the 71-84 range (American Psychiatric Association 2013). Though the level of ID may be described as 'borderline' (BID) or 'mild' (MID, IQ $50-70)$, in the MBID group a variety of problems accumulate, including poorer physical and mental health, social disadvantages, limited social support, overrepresentation in the forensic and mental health system (Lindsay et al. 2013; Wieland and Zitman 2015), and limited access to services including addiction treatment (Slayter 2010; Van Duijvenbode et al. 2015).

Rates of SU(D) in MBID vary greatly across studies, depending on sampling characteristics (Carroll Chapman and Wu 2012; Van Duijvenbode et al. 2015). Several demographic, contextual and diagnostic factors have been associated with SU(D) in MBID, such as younger than 30 years old, male, no structured daytime activities (To et al. 2014; VanDerNagel et al. 2011a), and living independently (Taggart et al. 2006; To et al. 2014). Furthermore, SU(D) in MBID is associated with psychiatric or behavioral (Chaplin et al. 2011; Didden et al. 2009) and forensic problems (Crocker et al. 2007; Hassiotis et al. 2011; Mcgillivray et al. 2015). For instance, among 39 patients with MBID in an inpatient treatment facility, 28\% abused alcohol, and 36\% drugs (Didden et al. 2009). In a psychiatric outpatient facility $(n=115), 17 \%$ alcohol misuse, $6 \%$ cannabis misuse and $3 \%$ cocaine misuse was found (Chaplin et al. 2011). In offenders with ID, several studies found SUD rates of approximately $60 \%$ (Crocker et al. 2007; Hassiotis et al. 2011; Mcgillivray et al. 2015). On the other hand, in several community based samples only $1 \%$ had a SUD diagnosis (Cooper et al. 2007; Taggart et al. 2006). As to SU, in a Belgian study in 123 individuals with MBID living independently, $48 \%$ smoked, $46 \%$ drank alcohol, and $2 \%$ used illicit substances in the past month (Swerts et al. 2017). Smoking rates in other community based samples of adults with ID, were much lower, for instance $1.9 \%$ in social education centers (Whitaker and Hughes 2003), and $9.3 \%$ in attenders at day care centers (Taylor et al. 2004). In adolescents with MBID, however, current smoking rates varied from 14\% (Emerson and Turnbull 2005) to 34\% (ŽunićPavlović et al. 2013) and in forensic ID samples smoking rates are reported to be up to $60 \%$ (Chester et al. 2011).

One of the challenges to assess rates of SU(D) in individuals with MBID is the lack of valid instruments. While self- reported SU in the general population is associated with high levels of under-report (see e.g., Fendrich et al. 2004), selfreport in individuals with MBID may be even more biased, especially when mainstream questionnaires are used (McGillicuddy 2006; VanDerNagel et al. 2013; Van Duijvenbode et al. 2015). However, the Substance use and misuse in intellectual disability - Questionnaire (SumID-Q, VanDerNagel et al. 2011b, 2013) - specifically developed to assess SU in MBID - had moderate to almost perfect agreement with biomarker analysis, and low levels of under-report (VanDerNagel et al. 2017). This may be the result of its stepby-step non-confrontational approach, in which SU picture recognition, knowledge, attitudes, and modeling are assessed before participants' SU is discussed. Based on previous studies, it is unclear if these factors are associated with SU status. For instance, though alcohol-related knowledge was poor in people with mild ID compared to non-ID groups (McCusker et al. 1993), alcohol and tobacco related knowledge in other studies were not associated with drinking and smoking in MBID (Swerts et al. 2017, Whitaker and Hughes 2003). Living together with smokers, however, was associated with smoking in two studies with children (Emerson et al. 2016) and adults (Whitaker and Hughes 2003) with ID. Knowledge about the relations between demographic, contextual, diagnostic, and SU related factors may contribute to an effective assessment, as well as to prevention and targeted treatment of SU(D) in this group. Furthermore, the majority of these studies were conducted abroad, and may not reflect the situation in the Netherlands, as both tobacco-, alcohol-, and illicit drug policies as well ID services vary between countries.

This study therefore used the SumID-Q to assess SU rates and risks in individuals with MBID who receive care from Dutch disability services. More specifically this crosssectional study aimed to determine lifetime and past month rates of alcohol, tobacco, cannabis, and stimulant use; to assess whether age at initiation of SU differs between a) current users, versus participants who desisted SU, and b) participants with mild ID (IQ 50-70) versus borderline ID (IQ 71-84); to identify demographical, contextual, and diagnostic risk factors for SU; and to assess the contribution of SU related factors (i.e., SU recognition, knowledge, attitude, and modeling) to a model for SU based on demographical, contextual, and diagnostic factors alone.

\section{Method}

\section{Participants}

In 2010 and 2011, individuals from 22 organizations of the Dutch Association of Healthcare Providers for People with Disabilities [Vereniging Gehandicaptenzorg Nederland, VGN] were invited to participate. These organizations provide 
a range of services, including supported living, institutional living, day-care centers, supported employment, and outpatient services. Five organizations declined to participate, and one was unable to fulfill the intention to participate. The remaining 16 organizations were asked to randomly select $10 \%$ of individuals with MBID in their facilities, and provide their contact details for recruitment purposes. However, several organizations could not or would not (because of privacy issues) provide a list based on level of ID, and therefore recruited participants themselves.

Individuals were eligible for participation if they 1) received care from one of these organizations, 2) were $\geq 18$ years old, 3) had MBID (IQ 50-85), and 4) had no such language or communication problems that participation was unfeasible.

A total of 600 individuals met our inclusion criteria, client representatives withheld consent in three individuals with a history of SUD, and in 26 individuals for other reasons, 147 individuals gave no informed consent, and data from five individuals were removed because of premature termination of the interview. Thus, 419 participants (70\%) were included in the sample (Table 1).

\section{Procedure}

Participants were visited at a venue of their choice by a trained research assistant who explained the study procedures using a DVD presentation and an illustrated leaflet with an easy to read text. Written informed consent was obtained from both the client and his or her (legal) representative. Participants received a small gift (worth approximately $€ 2.50$ / \$2.70) after the interview.

\section{Measures}

\section{Demographic, Contextual and Diagnostic Characteristics}

Data on demographic (date of birth, ethnicity, marital status), contextual (living arrangement, daytime activities), and diagnostic (BID, MID, full-scale IQ [TIQ]) characteristics were obtained from participants' professional caregivers.

\section{Substance Use}

The Substance use and misuse in Intellectual Disability Questionnaire (SumID-Q) (VanDerNagel et al. 2011b, 2013, 2017) assesses lifetime and past month (recent) SU. It is a structured interview that incorporates several strategies to reduce bias in self-report in individuals with MBID, including 1) adaptation of item structure and wording, 2) use of visual aids, and 3) a step by step non-confrontational approach. Administration of the SumID-Q takes 45 to $60 \mathrm{~min}$. It starts with assessing participants' familiarity with substances (tobacco, alcohol, cannabis, stimulants [i.e., cocaine and
Table 1 Participant Characteristics $(N=419)$

\begin{tabular}{|c|c|c|c|}
\hline Variable $(n)$ & Mean (SD) & $n$ & $\%$ \\
\hline \multicolumn{4}{|l|}{ Gender } \\
\hline Male & & 264 & 63.0 \\
\hline Age (404) & $34.5(14.4)$ & & \\
\hline \multicolumn{4}{|l|}{ Marital status (404) } \\
\hline Married & & 23 & 5.7 \\
\hline Divorced & & 24 & 5.9 \\
\hline Widowed & & 6 & 1.5 \\
\hline Other & & 351 & 83.9 \\
\hline \multicolumn{4}{|l|}{ Living arrangement (408) } \\
\hline Spouse $^{\mathrm{a}}$ & & 34 & 8.1 \\
\hline With children & & 6 & 1.4 \\
\hline Other family & & 12 & 2.9 \\
\hline Single & & 166 & 39.6 \\
\hline Group & & 190 & 45.3 \\
\hline \multicolumn{4}{|l|}{ Level of ID } \\
\hline Mild & & 273 & 65.2 \\
\hline Borderline & & 146 & 34.8 \\
\hline IQ (255) & $66.1(9.3)$ & & \\
\hline \multicolumn{4}{|l|}{ Etnicity (417) } \\
\hline Caucasian & & 383 & 91.4 \\
\hline Other & & 34 & 8.1 \\
\hline \multicolumn{4}{|l|}{ ID Service } \\
\hline Institutional grounds & & 66 & 15.8 \\
\hline Community facility & & 219 & 52.3 \\
\hline Other $^{\mathrm{b}}$ & & 134 & 32.0 \\
\hline
\end{tabular}

${ }^{\text {a }}$ Participants living with a spouse, with or without children

${ }^{\mathrm{b}}$ Includes supported living and case coordination services

amphetamines] and other illicit drugs) by showing substance related pictures from a standardized set, asking for each picture 'What is this?'. In the case of an incorrect response, the interviewer assesses if the participant can provide an adequate description of the substance when the mainstream name of the substance is presented ('What is weed?'). If the participant can neither identify any of the pictures related to a specific substance, nor describe it correctly, he or she is classified as not being familiar with this substance, and no further questions about this substance are asked. For each of the substances correctly recognized, further questions on substance knowledge and attitudes, and SU modeling are asked. Then, the participant is asked for each substance 'Did you ever use this?' (lifetime use; yes/no response format); and, if yes, 'Once or more often?' and 'How old were you the first time?' For the four substances most commonly used by individuals with MBID in the Netherlands (i.e., tobacco, alcohol, cannabis, and stimulants) (Van Laar and Van Ooyen-Houben 2016), SU patterns, and current SU is assessed. Reliability of the subscales in this study was good for picture recognition 
( $\alpha=.87)$, SU knowledge $(\alpha=.80)$, SU attitudes $(\alpha=.82)$, and acceptable for SU modeling $(\alpha=.76)$.

\section{Data Analyses}

Data were analyzed with SPSS (version 21). For each substance, composite scores were calculated for SU recognition (number of pictures correctly identified, range 0-8), knowledge (number of correct answers, maximum score $=8$ ), positive attitude towards SU (maximum score $=10$ ), and SU modeling (maximum $=15$ ).

To determine lifetime and current SU rates, we calculated percentages of participants who used 'never'/"once'/"more than once', and in the past month.

To assess whether age at initial SU differed between a) current users versus participants who desisted SU (i.e., participants who had used a substance at some time in their lives, but not in the last month), and b) participants with MID versus BID, we used Kaplan Meier curves, and the log rank test to compare survival times to age at initial use.

To identify demographical, contextual, and diagnostic risk factors for current tobacco and alcohol, and for lifetime cannabis and stimulant use, we calculated associations between these variables and SU status. For independent variables age and IQ, quartiles were used. Variables with univariate $p$ values $<.20$ were entered into a stepwise forward multiple logistic regression analysis comparing current users with non-users (for alcohol and tobacco use), and lifetime users with nonusers (cannabis and stimulants), and they remained in the model if this resulted in a significant $(p<.05)$ change in 2Loglikelihood.

To assess the contribution of SU recognition, knowledge, attitudes, and modeling to this model, we first assessed the univariate associations between these factors (divided in quartiles, or - if impossible due to skewed data - in two or three groups) and SU status within the subgroup of participants who were familiar with the substance of interest (recognition score $\geq 1$ ). Then, in a stepwise forward procedure, these variables were added to the model based on demographical, contextual, and diagnostic variables alone, if univariate $\mathrm{p}$ values were $<.20$, and they remained in the model if this resulted in a significant $(\mathrm{p}<.05)$ change in -2 Loglikelihood.

\section{Results}

\section{SU Rates}

Almost all participants $(n=407,97 \%)$ had used substances licit in the Netherlands (alcohol and tobacco) at least once in their lives, and a large proportion $(n=208,50 \%)$ had used at least once illicit substances (Table 2.). No significant differences in lifetime use ( $p s$ between .429 and .742) were found between participants with MID versus those with BID.

In the past month, only 81 participants (19\%) had not used substances at all. About a third $(n=142)$ used one substance, mainly tobacco $(n=64,15 \%)$, or alcohol $(n=77,18 \%)$. Almost half of our participants ( $n=196,47 \%)$ used more than one substance, mainly tobacco and alcohol $(n=133,32 \%)$ or tobacco, alcohol and cannabis $(n=50,12 \%)$. In total, $15 \%$ $(n=64)$ used cannabis or stimulants. No significant differences in current SU rates ( $p s$ between .558 and .812) were found between participants with MID versus BID.

\section{Age at Initial SU}

SU initiation occurred mainly during adolescence, though several participants started to use tobacco and alcohol at a much younger age (Fig. 1). Cannabis and stimulant use were typically initiated later in adolescence (Fig. 1).

Current smokers initiated smoking at a younger age than participants who desisted smoking (median $=13$ years, $\mathrm{IQR}=12-16$ years, versus median $=16$ years, $\mathrm{IQR}=13$ 18 years; $\left.\chi^{2}(1)=11.97, p<.001\right)$. Similarly, current drinkers initiated drinking at a younger age (median $=16$ years, IQR $=14-18$ years) compared to those who desisted (median $=17$ years, IQR $=15-17$ years; $\chi^{2}(1)=12.02, p<.001$ ), and current users of cannabis started using at a younger age (median $=15$ years, IQR $=13-16$ years $)$ than those who desisted $($ median $=17$ years, $\mathrm{IQR}=16-20$ years; $\left.\chi^{2}(1)=16.51, p<.001\right)$. No significant differences in age of initial use were found between current stimulant users (median $=24$ years, $\mathrm{IQR}=17-26)$ and participants who desisted $\left(\right.$ median $=18$ years, IQR $=16-21$ years; $\chi^{2}(1)=1.10$, $p=.293$ ). Median survival time to initial use did not differ significantly for any substance between participants with mild ID and those with borderline ID ( $p s$ between .221 and .853 ).

\section{Univariate and Multivariate Demographic, Contextual and Diagnostic Risk Factors}

Univariate and multivariate analyses of the demographic, contextual, and diagnostic characteristics versus current tobacco and alcohol use are presented in Table 3. Current tobacco use was significantly higher in males, and in those with a lack of structured daytime activities. Current alcohol use was significantly higher in males, and lower in the oldest two quartiles of participants (age $>31.9$ years) compared to the youngest quartile (age $<21.6$ years).

The multivariate model for current tobacco use contained male gender and lack of daytime activities. Though this model classified $63 \%$ of the participants correctly, it explained only a small proportion of smoking status variance (Table 3). Similarly, the final model for alcohol use, based on gender 
Table 2 Self-reported lifetime and past month SU rates \& ages of onset

\begin{tabular}{|c|c|c|c|c|c|c|c|c|c|c|c|}
\hline & \multicolumn{6}{|c|}{ Lifetime use } & \multirow{2}{*}{\multicolumn{2}{|c|}{$\frac{\text { Current use }}{\text { Yes }}$}} & \multicolumn{3}{|c|}{ Age of initial SU (years) } \\
\hline & \multicolumn{2}{|c|}{ Never } & \multicolumn{2}{|c|}{ Once } & \multicolumn{2}{|c|}{ More than once ${ }^{a}$} & & & & & \\
\hline & $n$ & $\%$ & $n$ & $\%$ & $n$ & $\%$ & $N$ & $\%$ & Mean & $\mathrm{SD}$ & Range \\
\hline Tobacco & 71 & 16.9 & 35 & 8.4 & 313 & 74.7 & 258 & 61.6 & 14.1 & 3.4 & $5-27$ \\
\hline Alcohol & 26 & 6.2 & 22 & 5.3 & 371 & 88.5 & 267 & 63.7 & 16.2 & 4.5 & $5-40$ \\
\hline Cannabis & 222 & 53.0 & 48 & 11.5 & 149 & 35.6 & 61 & 14.6 & 18.1 & 6.8 & $8-50$ \\
\hline Stimulants & 353 & 84.2 & 15 & 3.6 & 51 & 12.2 & 5 & 1.2 & 19.8 & 5.9 & $11-40$ \\
\hline Ecstasy & 345 & 88.5 & 15 & 3.6 & 33 & 7.9 & & & 18.6 & 4.7 & $11-37$ \\
\hline Non-prescribed opioids & 401 & 95.7 & 5 & 1.2 & 13 & 3.1 & & & 22.6 & 8.1 & $11-40$ \\
\hline Non-prescribed BZD & 400 & 95.5 & 4 & 1.0 & 15 & 3.6 & & & 25.2 & 11.4 & $13-44$ \\
\hline LSD & 407 & 97.1 & 6 & 1.4 & 6 & 1.4 & & & 17.9 & 3.9 & $11-25$ \\
\hline Psychedelic mushrooms & 386 & 92.1 & 17 & 4.1 & 16 & 3.8 & & & 18.6 & 4.9 & $11-40$ \\
\hline GHB & 404 & 96.4 & 9 & 2.1 & 6 & 1.4 & & & 18.9 & 3.9 & $12-25$ \\
\hline
\end{tabular}

$\mathrm{SD}=$ Standard deviation, $\mathrm{BZD}=$ benzodiazepines, $\mathrm{LSD}=$ Lysergic acid diethylamide, $\mathrm{GHB}=\gamma$-Hydroxybutyric acid

${ }^{\text {a } I n c l u d e s ~ p a r t i c i p a n t s ~ w i t h ~ c u r r e n t ~ S U ~}$

and age, explained little variance, but classified $65 \%$ of the participants correctly.

Lifetime use of both cannabis and stimulant use were significantly related to male gender and younger age, and in addition, lifetime stimulant use was significantly associated with lack of daytime activities (Table 4). The multivariate model for lifetime cannabis use based on age and gender classified $61 \%$ of the participants correctly. For lifetime stimulant use, male gender, younger age and lack of daytime activities contributed to the model, classifying $79 \%$ of the participants correctly. Compared to the models for current tobacco and alcohol use, these variables explained slightly more, but still small proportions of SU status variation.

\section{SU Picture Recognition, Knowledge, Attitudes and Modeling, as Risk Factors for SU}

For current tobacco and alcohol use, SU picture recognition, attitude, and modeling, but not knowledge were related to current smoking and drinking (Table 5). These factors also remained significant in the multivariate tobacco model, which
Fig. 1 Age at initial use of tobacco, alcohol, cannabis and stimulants

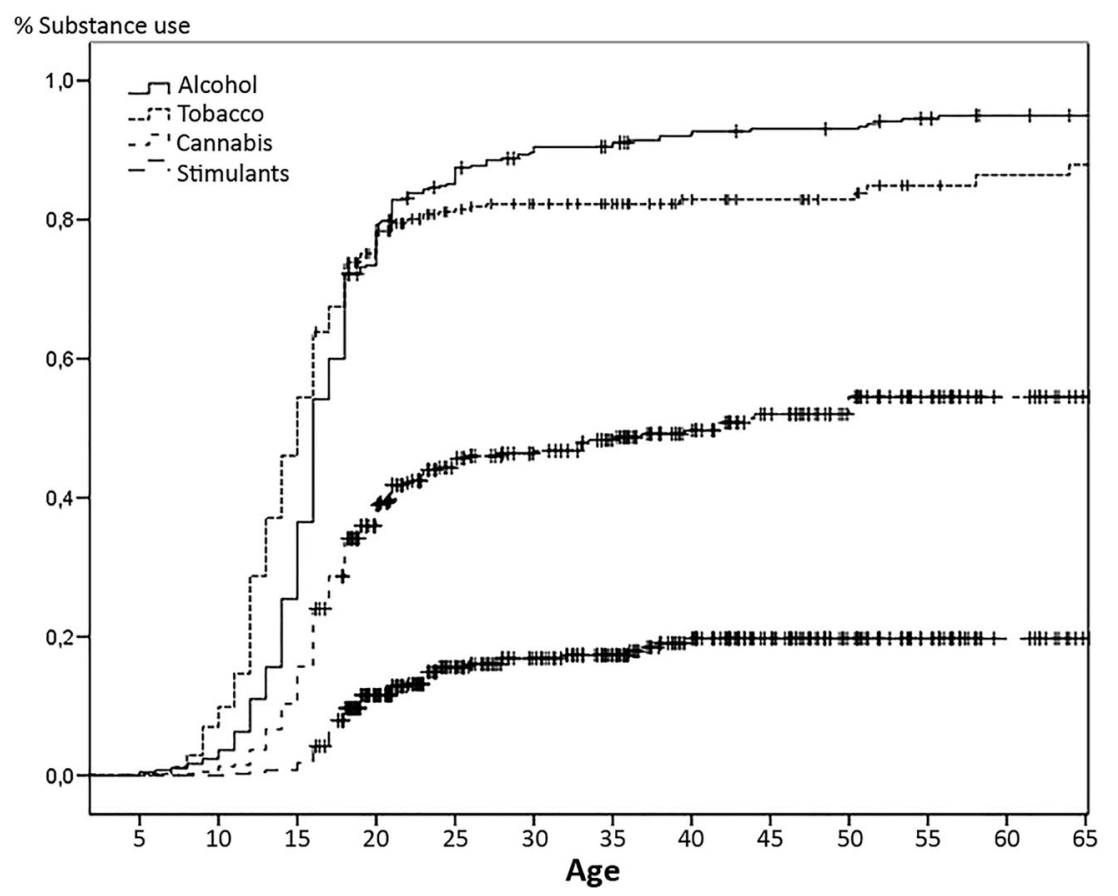


Table 3 Univariate and multivariate associations between demographic and contextual characteristics, level of ID; and current tobacco and alcohol use

\begin{tabular}{|c|c|c|c|c|c|c|c|c|}
\hline \multirow[t]{2}{*}{ Tobacco } & \multicolumn{4}{|c|}{ Univariate } & \multicolumn{4}{|c|}{ Multivariate model } \\
\hline & $\beta$ & OR & \multicolumn{2}{|c|}{$95 \% \mathrm{CI}$ OR } & $\beta$ & OR & \multicolumn{2}{|c|}{$95 \% \mathrm{CI}$ OR } \\
\hline Constant & & & & & .078 & & & \\
\hline \multicolumn{9}{|l|}{ Demographic } \\
\hline Male & $.53^{* *}$ & 1.71 & 1.14 & 2.56 & $.57 * *$ & 1.78 & 1.16 & 2.72 \\
\hline Age in years (Q1) & & 1 & & & & & & \\
\hline Q2 & .17 & 1.19 & .67 & 2.12 & & & & \\
\hline Q3 & $<.01$ & 1.0 & .57 & 1.77 & & & & \\
\hline Q4 & -.25 & .78 & .45 & 1.37 & & & & \\
\hline \multicolumn{9}{|l|}{ Contextual } \\
\hline Independent living & -.21 & .81 & .53 & 1.24 & & & & \\
\hline No daytime activities & $.71 *$ & 2.04 & 1.03 & 4.04 & $.76^{*}$ & 2.14 & 1.07 & 4.28 \\
\hline \multicolumn{9}{|l|}{ Intellectual functioning } \\
\hline Mild ID & -.09 & .91 & .60 & 1.38 & & & & \\
\hline TIQ (Q1), $(n=255)$ & & 1 & & & & & & \\
\hline Q2 & .05 & 1.05 & .53 & 2.09 & & & & \\
\hline Q3 & .33 & 1.38 & .67 & 2.85 & & & & \\
\hline Q4 & .25 & 1.28 & .62 & 2.66 & & & & \\
\hline \multicolumn{9}{|l|}{ Alcohol } \\
\hline \multicolumn{9}{|l|}{ Constant } \\
\hline \multicolumn{9}{|l|}{ Demographic } \\
\hline Male & .40 & 1.49 & .99 & 2.24 & .39 & 1.47 & .96 & 2.26 \\
\hline Age in years (Q1) & & 1 & & & & 1 & & \\
\hline Q2 & -.35 & .70 & .38 & 1.30 & -.39 & .68 & .37 & 1.25 \\
\hline Q3 & $-.64 *$ & .53 & .29 & .96 & $-.69 *$ & .50 & .28 & .92 \\
\hline Q4 & $-.76^{*}$ & .47 & .26 & .85 & $-.80 * *$ & .45 & .24 & .82 \\
\hline \multicolumn{9}{|l|}{ Contextual } \\
\hline Independent living & .21 & 1.24 & .80 & 1.90 & & & & \\
\hline No daytime activities & .21 & 1.23 & .65 & 2.31 & & & & \\
\hline \multicolumn{9}{|l|}{ Intellectual functioning } \\
\hline Mild ID & -.17 & .88 & .58 & 1.34 & & & & \\
\hline TIQ (Q1), $(n=255)$ & & 1 & & & & & & \\
\hline Q2 & .34 & 1.41 & .70 & 2.83 & & & & \\
\hline Q3 & .39 & 1.47 & .71 & 3.03 & & & & \\
\hline Q4 & .72 & 2.06 & .96 & 4.41 & & & & \\
\hline
\end{tabular}

$\mathrm{Q} 1=$ first quartile; $\mathrm{OR}=$ Odds Ratio, $\mathrm{ID}=$ intellectual disability, TIQ $=$ full scale IQ, $* p<.05, * * p<.01, * * * p<.001$ Multivariate model for current tobacco use: $\chi^{2}(2, n=387)=11.12, p=.004$. Cox \& Snell $\mathrm{R}^{2}=.029$, Nagelkerke $\mathrm{R}^{2}=.040$

Multivariate model for current alcohol use: $\chi^{2}(4, n=403)=10.68, p=.001$. Cox \& Snell $\mathrm{R}^{2}=0.026$, Nagelkerke $\mathrm{R}^{2}=0.036$

explained between $43 \%$ and $58 \%$ of the variance of smoking (Table 5), and correctly identified smoking status in $84 \%$ of the participants.

For alcohol use, picture recognition did not contribute significantly to the model based on gender, age, and attitude and modeling. This model predicted between $19 \%$ and $26 \%$ of the variance in current alcohol use, and correctly identified drinking status in $73 \%$ of the participants. Tobacco and alcohol related knowledge did not contribute significantly to the multivariate models (Table 5).
Participants who did not recognize any of the cannabis ( $n=23)$ or stimulant related pictures $(n=97)$ were excluded from the SU related analyses of these substances. For cannabis and stimulants, picture recognition, knowledge, attitude, and modeling contributed significantly to both the univariate associations and the multivariate model (Table 6). The models explained between $36 \%$ and $47 \%$ of lifetime cannabis use status, and between $36 \%$ and $54 \%$ of stimulant use, and correctly identified lifetime cannabis use in $76 \%$, and stimulant use in $84 \%$ of the participants. 
Table 4 Univariate and multivariate associations between demographic and contextual characteristics, level of ID; and lifetime cannabis and stimulant use

\begin{tabular}{|c|c|c|c|c|c|c|c|c|}
\hline \multirow[t]{2}{*}{ Cannabis } & \multicolumn{4}{|c|}{ Univariate } & \multicolumn{4}{|c|}{ Multivariate model } \\
\hline & $\beta$ & OR & \multicolumn{2}{|c|}{$95 \%$ CI OR } & $\beta$ & OR & \multicolumn{2}{|c|}{$95 \%$ CI OR } \\
\hline Constant & & & & & .10 & & & \\
\hline \multicolumn{9}{|l|}{ Demographic } \\
\hline Male & $.44 *$ & 1.55 & 1.03 & 2.32 & .34 & 1.41 & .92 & 2.16 \\
\hline Age in years (Q1) & & 1 & & & & 1 & & \\
\hline Q2 & .14 & 1.15 & .65 & 2.04 & .11 & 1.12 & .63 & 1.98 \\
\hline Q3 & -.35 & .71 & .40 & 1.24 & -.38 & .68 & .39 & 1.20 \\
\hline Q4 & $1.18^{* * *}$ & .31 & .17 & .56 & $-1.21 * * *$ & .30 & .16 & .55 \\
\hline \multicolumn{9}{|l|}{ Contextual } \\
\hline Independent living & -.23 & .79 & .52 & 1.21 & & & & \\
\hline No daytime activities & .39 & 1.47 & .80 & 2.70 & & & & \\
\hline \multicolumn{9}{|l|}{ Intellectual Functioning } \\
\hline Mild ID & -.07 & .93 & .62 & 1.40 & & & & \\
\hline TIQ, (Q1), $(n=255)$ & & 1 & & & & & & \\
\hline Q2 & .44 & 1.55 & .78 & 3.10 & & & & \\
\hline Q3 & .43 & 1.53 & .75 & 3.14 & & & & \\
\hline Q4 & .68 & 1.97 & .95 & 4.08 & & & & \\
\hline \multicolumn{9}{|l|}{ Stimulants } \\
\hline Constant & & & & & -2.73 & & & \\
\hline \multicolumn{9}{|l|}{ Demographic } \\
\hline Male & $1.36^{* * *}$ & 3.90 & 1.93 & 7.91 & $1.34 * * *$ & 3.82 & 1.83 & 7.98 \\
\hline Age in years (Q1) & $*$ & 1 & & & & 1 & & \\
\hline Q2 & .53 & 1.69 & .82 & 3.47 & .42 & 1.52 & .72 & 3.22 \\
\hline Q3 & .28 & 1.33 & .63 & 2.79 & -.02 & .98 & .45 & 2.16 \\
\hline Q4 & -.85 & .43 & .17 & 1.10 & $-1.04 *$ & .35 & .13 & .95 \\
\hline \multicolumn{9}{|l|}{ Contextual } \\
\hline Independent living & -.45 & .64 & .35 & 1.17 & & & & \\
\hline No daytime activities & $.83^{*}$ & 2.29 & 1.15 & 4.55 & $1.15^{* *}$ & 3.15 & 1.48 & 6.69 \\
\hline \multicolumn{9}{|l|}{ Intellectual Functioning } \\
\hline Mild ID & .08 & 1.08 & .62 & 1.89 & & & & \\
\hline TIQ, (Q1), $(n=255)$ & & 1 & & & & & & \\
\hline Q2 & .31 & 1.36 & .53 & 3.47 & & & & \\
\hline Q3 & .35 & 1.42 & .54 & 3.70 & & & & \\
\hline Q4 & .41 & 1.51 & .58 & 3.94 & & & & \\
\hline
\end{tabular}

$\mathrm{Q} 1$ = first quartile; $\mathrm{OR}=$ Odds Ratio, $\mathrm{ID}=$ intellectual disability, TIQ $=$ full scale $\mathrm{IQ}, * p<.05, * * p<.01, * * * p<.001$

Multivariate model for lifetime cannabis use: $\chi^{2}(4, n=391)=25.76, p<.001$. Cox \& Snell $\mathrm{R}^{2}=.064$, Nagelkerke $\mathrm{R}^{2}=.085$

Multivariate model for lifetime stimulant use: $\chi^{2}(5, n=379)=32.42, p<.001$. Cox \& Snell $\mathrm{R}^{2}=0.082$, Nagelkerke $\mathrm{R}^{2}=.139$

\section{Discussion}

A lack of knowledge about SU rates and risk factors in individuals with MBID in the Netherlands hinders targeted prevention and interventions. Available studies are often limited to highly selected samples, report highly divergent rates, and provide limited knowledge on demographical, contextual, diagnostic and other risk factors. Furthermore, it is unclear whether international studies are relevant for the situation in the Netherlands. Therefore, we assessed SU rates and risks in individuals with MBID in several Dutch ID services.

In our sample, the rates of current smoking (62\%), current cannabis and other illicit drug use (15\%), but not drinking (64\%) were very high, given the SU rates in the Dutch general population (past month tobacco use $\approx 25 \%$, alcohol use $\approx$ $77 \%$, cannabis use $\approx 5 \%$, stimulant use $<1 \%$ ) (Van Laar and 
Table 5 Univariate and multivariate associations between demographic, contextual characteristics, SU related measures; and current smoking and drinking in participants familiar with the substance of interest $(n=419)$

\begin{tabular}{|c|c|c|c|c|c|c|c|c|}
\hline \multirow{3}{*}{$\begin{array}{l}\text { Tobacco } \\
\text { Constant }\end{array}$} & \multicolumn{4}{|l|}{ Univariate } & \multicolumn{4}{|c|}{ Multivariate model } \\
\hline & \multirow[t]{2}{*}{$\beta$} & \multirow[t]{2}{*}{ OR } & \multicolumn{2}{|c|}{$95 \% \mathrm{CI}$} & \multirow{2}{*}{$\begin{array}{c}B \\
-3.18\end{array}$} & \multirow[t]{2}{*}{ OR } & \multicolumn{2}{|c|}{$95 \% \mathrm{CI}$} \\
\hline & & & & & & & & \\
\hline \multicolumn{9}{|l|}{ Variables from step 1} \\
\hline Male gender & $.53 * *$ & 1.71 & 1.14 & 2.56 & .56 & 1.75 & .94 & 3.24 \\
\hline No daytime activities & $.71^{*}$ & 2.04 & 1.03 & 4.04 & -.81 & .45 & .18 & 1.13 \\
\hline \multicolumn{9}{|l|}{ SU related measurements } \\
\hline Recognition $^{\mathrm{a}}$ & $1.39 * * *$ & 4.02 & 2.10 & 7.69 & $1.64 * * *$ & 5.14 & 2.00 & 13.20 \\
\hline Knowledge (Q1) & & 1 & & & & & & \\
\hline Q2 & .37 & 1.45 & .63 & 3.35 & & & & \\
\hline Q3 & .17 & 1.19 & .53 & 2.64 & & & & \\
\hline Q4 & -.19 & .83 & .36 & 1.91 & & & & \\
\hline Attitude (score 0-1) & & 1 & & & & & & \\
\hline Score $2-3$ & $2.48 * * *$ & 11.92 & 6.75 & 21.05 & $2.54 * * *$ & 12.65 & 6.59 & 24.30 \\
\hline Score $\geq 4$ & $4.46^{* * *}$ & 86.14 & 36.07 & 205.75 & $4.17 * * *$ & 64.60 & 25.82 & 161.64 \\
\hline Modeling (Q1) & & 1 & & & 1 & & & \\
\hline Q2 & $.69 * *$ & 2.00 & 1.22 & 3.29 & $.73 *$ & 2.08 & 1.02 & 4.25 \\
\hline Q3 & $1.42 * * *$ & 4.13 & 2.24 & 7.61 & $1.28 * *$ & 3.58 & 1.46 & 8.76 \\
\hline Q4 & $1.62 * * *$ & 5.07 & 2.58 & 9.95 & $1.15^{*}$ & 3.18 & 1.23 & 8.25 \\
\hline \multicolumn{9}{|l|}{ Alcohol } \\
\hline Constant & & & & & -1.22 & & & \\
\hline \multicolumn{9}{|l|}{ Variables from step 1} \\
\hline Male gender & .40 & 1.49 & .99 & 2.24 & .16 & 1.17 & .72 & 1.90 \\
\hline Age (Q1) & & 1 & & & 1 & & & \\
\hline Q2 & -.35 & .70 & .38 & 1.30 & .52 & 1.68 & .84 & 3.35 \\
\hline Q3 & $-.64 *$ & .53 & .29 & .96 & .12 & 1.12 & .58 & 2.18 \\
\hline Q4 & $-.76^{*}$ & .47 & .26 & .85 & -.09 & .91 & .49 & 1.72 \\
\hline \multicolumn{9}{|l|}{ SU related measurements } \\
\hline Recognition $^{\mathrm{a}}$ & $.79 * *$ & 2.21 & 1.30 & 3.78 & & & & \\
\hline Knowledge ${ }^{\mathrm{b}}$ & .38 & 1.47 & .98 & 2.20 & & & & \\
\hline Attitude (Q1) & & 1 & & & 1 & & & \\
\hline Q2 & $1.11 * * *$ & 3.02 & 1.72 & 5.32 & $1.16^{* * *}$ & 3.20 & 1.72 & 5.94 \\
\hline Q3 & $1.64 * * *$ & 5.15 & 2.81 & 9.45 & $1.55 * * *$ & 4.70 & 2.42 & 9.12 \\
\hline Q4 & $2.08^{* * * *}$ & 7.97 & 4.26 & 14.91 & $1.88 * * *$ & 6.57 & 3.39 & 12.71 \\
\hline Modeling (Q1) & & 1 & & & 1 & & & \\
\hline Q2 & $.78 * *$ & 2.17 & 1.29 & 3.656 & $.81 * *$ & 2.24 & 1.26 & 4.01 \\
\hline Q3 & $1.37 * * *$ & 3.94 & 2.08 & 7.490 & $1.15 * * *$ & 3.15 & 1.54 & 6.46 \\
\hline Q4 & $1.57 * * *$ & 4.80 & 2.63 & 8.760 & $1.25 * * *$ & 3.48 & 1.75 & 6.92 \\
\hline
\end{tabular}

$\mathrm{Q} 1=$ first quartile; OR = Odds Ratio, $* p<.05, * * p<.01, * * * p<.001$

$\mathrm{ID}=$ intellectual disability, TIQ $=$ full scale IQ, SU = Substance Use

${ }^{\text {a }}$ Participants with below maximum recognition score versus participants with maximum score

${ }^{\mathrm{b}}$ Participants with knowledge score $0-5$ versus $>5$ Expanded model for current tobacco use: $\chi^{2}(7, n=385)=215.14, p<.001$. Cox \& Snell $\mathrm{R}^{2}=.428$, Nagelkerke $\mathrm{R}^{2}=.584$

Expanded model for current alcohol use: $\chi^{2}(10, n=399)=83.16, p<.001$. Cox \& Snell $\mathrm{R}^{2}=.188$, Nagelkerke $\mathrm{R}^{2}=.259$

Van Ooyen-Houben 2016). Compared to studies in the MBID population (Carroll Chapman and Wu 2012; Emerson and Turnbull 2005; McGillicuddy 2006; Swerts et al. 2017;
Taylor et al. 2004; Whitaker and Hughes 2003; ŽunićPavlović et al. 2013), including the Flemish SumID-Q study (Swerts et al. 2017), all SU rates seem rather high, but illicit 
Table 6 Univariate and multivariate associations between demographic, contextual characteristics, SU related measures; and lifetime cannabis and stimulant use in participants with ID who are familiar with substance of interest (cannabis $n=396$, stimulants $n=322$ )

\begin{tabular}{|c|c|c|c|c|c|c|c|c|}
\hline \multirow[t]{2}{*}{ Cannabis } & \multicolumn{4}{|c|}{ Univariate } & \multicolumn{4}{|c|}{ Multivariate model } \\
\hline & $\beta$ & OR & \multicolumn{2}{|c|}{$95 \% \mathrm{CI}$} & $B$ & OR & \multicolumn{2}{|c|}{$95 \% \mathrm{CI}$} \\
\hline Constant & & & & & -3.80 & & & \\
\hline \multicolumn{9}{|l|}{ Variables from step 1} \\
\hline Male gender & .39 & 1.48 & .98 & 2.25 & -.26 & .77 & .43 & 1.36 \\
\hline Age (Q1) & & 1 & & & & 1 & & \\
\hline Q2 & .17 & 1.19 & .67 & 2.11 & -.27 & .76 & .32 & 1.81 \\
\hline Q3 & -.35 & .70 & .40 & 1.23 & .50 & 1.66 & .72 & 3.80 \\
\hline Q4 & $-.97 * *$ & .38 & .21 & .70 & -.31 & .73 & .33 & 1.65 \\
\hline \multicolumn{9}{|l|}{ SU related measurements } \\
\hline Recognition $^{\mathrm{a}}$ & $1.84 * * *$ & 6.28 & 4.03 & 9.80 & $1.20 * * *$ & 3.33 & 1.86 & 5.98 \\
\hline Knowledge (Q1) & & 1 & & & & 1 & & \\
\hline Q2 & $1.42 * * *$ & 4.14 & 2.24 & 7.67 & $1.10 * *$ & 3.01 & 1.42 & 6.40 \\
\hline Q3 & $2.00 * * *$ & 7.41 & 3.76 & 14.59 & $1.34 * * *$ & 3.81 & 1.68 & 8.64 \\
\hline Q4 & $2.95 * * *$ & 19.19 & 8.85 & 41.61 & $2.11 * * *$ & 8.26 & 3.22 & 21.21 \\
\hline Attitude (score 0-1) & & 1 & & & & 1 & & \\
\hline Score 2 & $1.44 * * *$ & 4.22 & 2.59 & 6.86 & $1.33 * * *$ & 3.79 & 2.09 & 6.88 \\
\hline Score $\geq 3$ & $2.90 * * *$ & 18.26 & 8.74 & 38.15 & $2.19 * * *$ & 8.94 & 3.63 & 22.03 \\
\hline Modeling (Q1) & & 1 & & & & 1 & & \\
\hline Q2 & .37 & 1.45 & .75 & 2.79 & -.13 & .88 & .40 & 1.94 \\
\hline Q3 & $1.27 * * *$ & 3.55 & 2.07 & 6.10 & .61 & 1.85 & .93 & 3.65 \\
\hline Q4 & $2.18 * * *$ & 8.86 & 4.37 & 18.00 & $1.04 *$ & 2.84 & 1.17 & 6.89 \\
\hline \multicolumn{9}{|l|}{ Stimulants } \\
\hline Constant & & & & & -9.94 & & & \\
\hline \multicolumn{9}{|l|}{ Variables from step 1} \\
\hline Male gender & $1.15^{* *}$ & 3.14 & 1.53 & 6.45 & .33 & 1.39 & .52 & 3.69 \\
\hline Age (Q1) & & 1 & & & & 1 & & \\
\hline Q2 & .49 & 1.64 & .78 & 3.43 & 1.20 & 3.33 & .77 & 14.39 \\
\hline Q3 & .28 & 1.33 & .62 & 2.85 & 1.21 & 3.35 & .84 & 13.34 \\
\hline Q4 & -.76 & .47 & .18 & 1.22 & .69 & 1.99 & .50 & 8.03 \\
\hline No daytime activities & $.87 *$ & 2.38 & 1.15 & 4.91 & .80 & 2.22 & .75 & 6.56 \\
\hline \multicolumn{9}{|l|}{ SU related measurements } \\
\hline Recognition (Q1) & & 1 & & & & 1 & & \\
\hline Q2 & $1.71 *$ & 5.51 & 1.11 & 27.39 & 1.98 & 7.21 & .75 & 69.67 \\
\hline Q3 & $2.74 * * *$ & 15.58 & 3.47 & 68.77 & $2.87 * *$ & 17.68 & 2.10 & 148.92 \\
\hline Q4 & $3.82 * * *$ & 45.60 & 10.50 & 198.12 & $3.76 * * *$ & 42.86 & 4.95 & 371.41 \\
\hline Knowledge (Q1) & & 1 & & & & 1 & & \\
\hline Q2 & $2.80 * *$ & 16.61 & 2.18 & 126.57 & $2.65^{*}$ & 14.12 & 1.37 & 145.98 \\
\hline Q3 & $3.02 * *$ & 20.51 & 2.67 & 157.70 & $2.45^{*}$ & 11.58 & 1.15 & 117.04 \\
\hline Q4 & $3.78^{* * *}$ & 43.59 & 5.68 & 334.29 & $2.81 *$ & 16.52 & 1.56 & 174.84 \\
\hline Attitude (score 0) & & 1 & & & & 1 & & \\
\hline Score 1 & $1.27 * * *$ & 3.56 & 1.78 & 7.15 & $.97 *$ & 2.63 & 1.01 & 6.89 \\
\hline Score $\geq 2$ & $2.51 * * *$ & 12.32 & 5.85 & 25.91 & $2.72 * * *$ & 15.14 & 4.34 & 52.77 \\
\hline Modeling (No/Yes) & $1.59^{* * *}$ & 4.90 & 2.71 & 8.88 & & & & \\
\hline
\end{tabular}

$\mathrm{Q} 1=$ first quartile; $\mathrm{OR}=$ Odds Ratio, $* p<.05, * * p<.01, * * * p<.001, \mathrm{ID}=$ intellectual disability, TIQ $=$ full scale IQ, SU $=$ Substance Use

${ }^{\text {a }}$ Participants with below maximum recognition score versus participants with maximum score

Expanded model ifetime cannabis use: $\chi^{2}(13, n=347)=151.99, p<.001$. Cox \& Snell $\mathrm{R}^{2}=0.355$, Nagelkerke $\mathrm{R}^{2}=.474$

Expanded model lifetime stimulant use: $\chi^{2}(14, n=246)=111.36, p<.001$. Cox \& Snell $\mathrm{R}^{2}=0.364$, Nagelkerke $\mathrm{R}^{2}=.543$ 
drug use in our study stands out. This may be explained by higher levels of use and willingness to disclose such use, related the Dutch cannabis policies (i.e., users are seldomly prosecuted) that mislead some individuals with MBID to think cannabis use is legal in the Netherlands (VanDerNagel et al. 2013, 2017). While sampling differences may contribute to the different rates between the Dutch and Flemish SumID studies, the exclusion of individuals with BID in the latter does not explain our higher rates since we did not find differences between BID and MID in SU rates, and for that matter neither in age of initial use.

As described in other populations (see e.g., Carroll Chapman and Wu 2012; McGillicuddy 2006), SU initiation occurred typically in adolescence, but several participants initiated SU at primary school age. Participants who were current users, had started at younger ages than those who desisted, corroborating findings in individuals without MBID (Bolland et al. 2016; Nelson et al. 2015; Prince van Leeuwen et al. 2014). Though gender, age and lack of daytime activities were associated with SU, independent living and level of ID (MID versus BID) were not, contrary to suggestions from other studies (e.g., To et al. 2014; Taggart et al. 2006). Moreover, demographic and contextual factors were of little relevance to the final models in which substance picture recognition, knowledge, attitude and modeling were added. Substance related knowledge was significantly higher in users compared to non-users of illicit substances, but not in users of licit substances, as was found in the Flemish SumID- $Q$ study (Swerts et al. 2017). For all substances, substance related positive attitudes and SU modeling were associated with an increase in SU likelihood, as previous studies in MBID found for smoking and drinking (Emerson et al. 2016; Swerts et al. 2017; Whitaker and Hughes 2003).

\section{Limitations and Future Research Directions}

Since this study had a cross-sectional design, there is a risk of recall bias and causality between risk factors and SU status cannot be established. For instance, SU knowledge, and positive SU attitudes could lead to SU, but SU in turn can increase SU knowledge and positive attitudes. In addition, though this study concerns a relatively unselected and relatively large sample of individuals with MBID receiving care from a variety of settings, we cannot claim that this sample is representative of MBID population. Furthermore, since clustered randomized sampling proved to be unfeasible given the divergent ways participating organizations were sized and structured, and because of the lack of non-response analysis, selection bias cannot be ruled out.

Thus, prospective studies in cohorts of individuals with MBID who have not initiated in SU are needed. Given the young age at SU initiation in some of our participants, as well as those in other Dutch studies (e.g. Kiewik et al. 2016), these studies best start with samples of primary school aged participants. Since we did not distinguish between problematic SU, and non-problematic SU, further studies will also need to assess if and how risk factors are related to SUD. Given the high - and from a health and social perspective alarming - SU rates in our study, preventative actions that are currently in place apparently are insufficient for individuals with MBID. This calls for increased efforts from addiction facilities and ID services to develop, implement and study effective interventions. These interventions should target variables such as SU related attitudes, and SU modeling, including peer influences but also modeling by staff members. Since demographic, contextual and diagnostic account only for a small part of the variance in SU status, such interventions need to be available to all individuals with MBID. In addition, in order to identify (risk factors of) SU timely, a case-by-case approach using measurements such as the $\operatorname{SumID-} Q$ is needed.

Acknowledgements This study was funded by ZonMW, the Netherlands Organization for Health Research and Development (project number 60-60600-97-158). The authors wish to thank participants, staff members, institutions, and research assistants for their contributions.

Author Contributions JVDN: designed and executed the study, analyzed the data and wrote the paper. MK and RD: collaborated with the design of the study, and writing and editing of the final manuscript. HK: collaborated with the design and data analyses. MVD: supervised data collection and assisted with the data analyses. JVDP: supervised design, data analyses and collaborated writing the manuscript. JB and CDJ: collaborated with the design of the study, and writing of the manuscript.

\section{Compliance with Ethical Standards}

\section{Conflict of Interest None.}

Approval The study was approved by the Medical Ethical Review Board Twente (NL27716.044.09) and was conducted in accordance with the Declaration of Helsinki (World Medical Association 2013).

Open Access This article is distributed under the terms of the Creative Commons Attribution 4.0 International License (http:// creativecommons.org/licenses/by/4.0/), which permits unrestricted use, distribution, and reproduction in any medium, provided you give appropriate credit to the original author(s) and the source, provide a link to the Creative Commons license, and indicate if changes were made.

\section{References}

American Psychiatric Association. (2013). Diagnostic and statistical manual of mental disorders: DSM-5. Washington, DC: American Psychiatric Association.

Bolland, K. A., Bolland, J. M., Tomek, S., Devereaux, R. S., Mrug, S., \& Wimberly, J. C. (2016). Trajectories of adolescent alcohol use by gender and early initiation status. Youth \& Society, 48, 3-32.

Burgard, J. F., Donohue, B., Azrin, N. H., \& Teichner, G. (2000). Prevalence and treatment of substance abuse in the mentally retarded population: An empirical review. Journal of Psychoactive Drugs, 32, 293-298. 
Carroll Chapman, S. L., \& Wu, L.-T. (2012). Substance abuse among individuals with intellectual disabilities. Research in Developmental Disabilities, 33, 1147-1156.

Chaplin, E., Gilvarry, C., \& Tsakanikos, E. (2011). Recreational substance use patterns and co-morbid psychopathology in adults with intellectual disability. Research in Developmental Disabilities, 32, 2981-2986.

Chester, V., Green, F., \& Alexander, R. (2011). An audit of a smoking cessation programme for people with an intellectual disability resident in a forensic unit. Advances in Mental Health and Intellectual Disabilities, 5, 33-41.

Cooper, S.-A., Smiley, E., Morrison, J., Williamson, A., \& Allan, L. (2007). Mental ill-health in adults with intellectual disabilities: Prevalence and associated factors. The British Journal of Psychiatry: the Journal of Mental Science, 190, 27-35.

Crocker, A. G., Côté, G., Toupin, J., \& St-Onge, B. (2007). Rate and characteristics of men with an intellectual disability in pre-trial detention. Journal of Intellectual \& Developmental Disability, 32, $143-152$.

Didden, R., Embregts, P., Van der Toorn, M., \& Laarhoven, N. (2009). Substance abuse, coping strategies, adaptive skills and behavioral and emotional problems in clients with mild to borderline intellectual disability admitted to a treatment facility: A pilot study. Research in Developmental Disabilities, 30, 927-932.

Emerson, E., \& Turnbull, L. (2005). Self reported smoking and alcohol use among adolescents with intellectual disabilities. Journal of Intellectual Disabilities, 9, 58-69.

Emerson, E., Hatton, C., Robertson, J., \& Baines, S. (2016). Exposure to second hand tobacco smoke at home and child smoking at age 11 among British children with and without intellectual disability. Journal of Intellectual Disability Research, 60, 274-281.

Fendrich, M., Johnson, T. P., Wislar, J. S., Hubbell, A., \& Spiehler, V. (2004). The utility of drug testing in epidemiological research: Results from a general population survey. Addiction, 99, 197-208.

Hassiotis, A., Gazizova, D., Akinlonu, L., Bebbington, P., Meltzer, H., \& Strydom, A. (2011). Psychiatric morbidity in prisoners with intellectual disabilities: Analysis of prison survey data for England and Wales. The British Journal of Psychiatry: the Journal of Mental Science, 199, 156-157.

Kiewik, M., VanDerNagel, J. E. L., Kemna, L. E. M., Engels, R. C. M. E., \& DeJong, C. A. J. (2016). Substance use prevention program for adolescents with intellectual disabilities on special education schools: A cluster randomised control trial. Journal of Intellectual Disability Research, 60, 191-200.

Lindsay, W. R., Carson, D., Holland, A. J., Taylor, J. L., O’Brien, G., \& Wheeler, J. R. (2013). The impact of known criminogenic factors on offenders with intellectual disability: Previous findings and new results on ADHD. Journal of Applied Research in Intellectual Disabilities, 26, 71-80.

McCusker, C. G., Clare, I. C. H., Cullen, C., \& Reep, J. (1993). Alcoholrelated knowledge and attitudes in people with a mild learning disability - the effects of a "sensible drinking" group. Journal of Community \& Applied Social Psychology, 3, 29-40.

McGillicuddy, N. B. (2006). A review of substance use research among those with mental retardation. Mental Retardation and Developmental Disabilities Research Reviews, 12, 41-47.

Mcgillivray, J. A., \& Moore, M. R. (2001). Substance use by offenders with mild intellectual disability. Journal of Intellectual \& Developmental Disability, 26, 297-310.

Mcgillivray, J. A., Gaskin, C. J., Newton, D. C., \& Richardson, B. A. (2015). Substance use, offending, and participation in alcohol and drug treatment Programmes : A comparison of prisoners with and without intellectual disabilities. Journal of Applied Research in Intellectual Disabilities, 29, 289-294.

Nelson, S. E., Van Ryzin, M. J., \& Dishion, T. J. (2015). Alcohol, marijuana, and tobacco use trajectories from age 12 to 24 years:
Demographic correlates and young adult substance use problems. Development and Psychopathology, 27, 253-277.

Prince van Leeuwen, A., Creemers, H. E., Verhulst, F. C., Vollebergh, W. A. M., Ormel, J., Van Oort, F., \& Huizink, A. C. (2014). Legal substance use and the development of a DSM-IV cannabis use disorder during adolescence: The TRAILS study. Addiction, 109, 303311.

Slayter, E. M. (2010). Disparities in access to substance abuse treatment among people with intellectual disabilities and serious mental illness. Health \& Social Work, 35, 49-59.

Swerts, C., Vandevelde, S., VanDerNagel, J. E., Vanderplasschen, W., Claes, C., \& De Maeyer, J. (2017). Substance use among individuals with intellectual disabilities living independently in Flanders. Research in Developmental Disabilities, 63, 107-117.

Taggart, L., McLaughlin, D., Quinn, B., \& Milligan, V. (2006). An exploration of substance misuse in people with intellectual disabilities. Journal of Intellectual Disability Research, 50, 588-597.

Taylor, N. S., Standen, P. J., Catajar, P., Fox, D., \& Wilson, D. N. (2004). Smoking prevalence and knowledge of associated risks in adult attenders at day centres for people with learning disabilities. Journal of Intellectual Disability Research, 48, 239-244.

To, W. T., Neirynck, S., Vanderplasschen, W., Vanheule, S., \& Vandevelde, S. (2014). Substance use and misuse in persons with intellectual disabilities (ID): Results of a survey in ID and addiction services in Flanders. Research in Developmental Disabilities, 35, 1-9.

Van Duijvenbode, N., VanDerNagel, J. E. L., Didden, R., Engels, R. C. M. E., Buitelaar, J. K., Kiewik, M., \& De Jong, C. A. J. (2015). Substance use disorders in individuals with mild to borderline intellectual disability: Current status and future directions. Research in Developmental Disabilities, 38, 319-328.

Van Laar, M. W., \& Van Ooyen-Houben, M. M. J. (2016). Nationale Drug Monitor [National drug monitor]. (2015). Retrieved March 4, 2016, from https://assets.trimbos.nl/docs/24dd30ba-464f4dcd-a740-20ac058d310b.pdf.

VanDerNagel, J. E. L., Kiewik, M., Buitelaar, J. K., \& De Jong, C. A. J. (2011a). Staff perspectives of substance use and misuse among adults with intellectual disabilities enrolled in Dutch disability services. Journal of Policy and Practice in Intellectual Disabilities, 8 , 143-149.

VanDerNagel, J. E. L., Kiewik, M., Van Dijk, M., De Jong, C. A. J., \& Didden, R. (2011b). Handleiding SumID-Q, Meetinstrument voor het in kaart brengen van Middelengebruik bij mensen met een lichte verstandelijke beperking [manual of the SumID-Q. An instrument to assess substance use in individuals with a mild intellectual disability]. Deventer: Tactus.

VanDerNagel, J. E. L., Kemna, L. E. M., \& Didden, R. (2013). Substance use among persons with mild intellectual disability: Approaches to screening and interviewing. NADD Bulletin, 16, 87-92.

VanDerNagel, J. E. L., Kiewik, M., Dijk, M. V., Didden, R., Korzilius, H. P. L. M., Palen, J., et al. (2017). Substance use in individuals with mild to borderline intellectual disability: A comparison between self-report, collateral-report and biomarker analysis. Research in Developmental Disabilities, 63, 151-159.

Whitaker, S., \& Hughes, M. (2003). Prevalence and influence on smoking in people with learning disabilities. British Journal of Developmental Disabilities, 49, 91-97.

Wieland, J., \& Zitman, F. G. (2015). It is time to bring borderline intellectual functioning back into the main fold of classification systems. British Journal of Psychiatry Bulletin, 1-3.

World Medical Association. (2013). World medical association declaration of Helsinki: Ethical principles for medical research involving human subjects. JAMA, 310, 2191-2194.

Žunić-Pavlović, V., Pavlović, M., \& Glumbić, N. (2013). Drug use in adolescents with mild intellectual disability in different living arrangements. Drugs: education, prevention and policy, 20, 399-407. 